\title{
Contribuições da Abordagem Ciência, Tecnologia e Sociedade para a Humanização do Trabalho Docente
}

\author{
Luciana Flôr Correa ${ }^{1}$ \\ Walter Antonio Bazzo 2
}

\begin{abstract}
Resumo
0 objetivo do presente artigo é refletir sobre alguns aspectos que evidenciam que a abordagem Ciência, Tecnologia e Sociedade (CTS), nos cursos de formação de professores, pode constituir-se em importante contribuição para a promoção de ambientes de trabalho que motivem a cooperação, a humanização e o posicionamento crítico em relação ao processo civilizatório, uma vez que 0 atual modelo hegemônico prioriza a competição, minimiza as questões humanas e leva o sujeito ao comodismo e à sujeição. Utilizando os recursos da pesquisa bibliográfica, para introduzir o tema enfocaremos a situação e os desafios do trabalho docente, sobretudo na esfera universitária. Na sequência, abordaremos a relação entre a educação e o trabalho na era do capital, e, na parte final, faremos uma breve análise da importância do enfoque CTS para a possível desalienação e a promoção de ambientes de trabalho docente favoráveis ao desenvolvimento humano.
\end{abstract}

Palavras-chave: Trabalho docente. Formação acadêmica. Ciência, Tecnologia e Sociedade. Desenvolvimento humano.

\footnotetext{
${ }^{1}$ Assistente social, mestre em Educação, professora da Universidade do Sul de Santa Catarina (Unisul). Doutoranda do Programa de Pós-Graduação em Educação Científica e Tecnológica (PPGECT) da Universidade Federal de Santa Catarina (UFSC). luciana.flor@unisul.br

${ }^{2}$ Engenheiro mecânico, doutor em Educação, professor do Departamento de Engenharia Mecânica e do Programa de Pós-Graduação em Educação Científica e Tecnológica (PPGECT) da Universidade Federal de Santa Catarina (UFSC) e coordenador do Núcleo de Estudos e Pesquisas em Educação Tecnológica (Nepet/UFSC).walter.bazzo@ufsc.br
} 


\title{
CONTRIBUTIONS OF THE SCIENCE, TECHNOLOGY AND SOCIETY APPROACH TO HUMANIZATION OF TEACHING WORK
}

\begin{abstract}
The aim of this article is to reflect on some aspects that demonstrate that the Science, Technology and Society (STS) approach in teacher training courses can be an important contribution to the promotion of work environments that motivate cooperation, humanization and critical positioning in relation to the civilizing process; since the current hegemonic model prioritizes competition, minimizes human issues and leads the subject to self-indulgence and subjection. Using the resources of the bibliographical research, to introduce the subject we will focus the situation and the challenges of the teaching work, mainly in the university sphere. Next, we will address the relationship between education and work in the age of capital. And in the final section, we will briefly analyze the importance of the STS approach to the possible alienation and promotion of teaching work environments conducive to human development.
\end{abstract}

Keywords: Teaching work. Academic education. Science, Technology and Society. Human development. 
As transformações sociais que vêm ocorrendo desde a segunda metade do século 20 estão gerando mudanças profundas no mundo do trabalho. Além disso, o próprio conceito de trabalho vem sofrendo alterações ao longo da História.

Durante muitos anos o trabalho serviu para a manutenção e a reprodução biológica do ser humano, sendo desempenhado sob a forma de coleta, extrativo e, mais tarde, pesca, caça e pastoreio (MORETTI, 2012). Com o advento da agricultura, essa relação começou a modificar-se, pois a ideia de produção de excedentes veio acompanhada da ideia de acumulação, poder e escravidão. No mundo grego e romano, por exemplo, somente ao trabalho de direção das atividades agrícolas se reconhecia dignidade e importância social; prestígio totalmente negado ao comércio, artesanato e atividades manuais. Os alicerces da produção social deslocaram-se da agricultura para a indústria apenas quando o comércio se sobrepôs ao trabalho agrícola e ampliou suas atividades (MORETTI, 2012).

A revolução industrial, que se iniciou no século 18, também foi outro fator de alteração da concepção de trabalho, uma vez que as fábricas juntaram num só espaço trabalhadores e máquinas, aumentando a especialização das tarefas e a divisão do trabalho, contribuindo para o afastamento das pessoas do conteúdo de suas próprias atividades.

Nos últimos anos temos vivido ainda uma outra revolução, a qual insere o trabalhador na era do conhecimento, requerendo dele o desenvolvimento de habilidades para lidar com um mundo extremamente complexo, incerto e instável (MORETTI, 2012). A partir de então, o trabalho passou a ser visto como meio de promoção profissional, econômica e social e a falta de trabalho passou a desencadear a marginalização e a deterioração pessoal. Ou seja, o trabalho foi deixando de ser mero instrumento do homem para se tornar a vida do homem.

Apesar do trabalho ter uma trajetória e um caráter, por vezes opressor na História da humanidade, Marx (1983), em seus estudos, o posiciona como um aspecto natural e intrínseco do ser humano. Para ele, o trabalho é um processo entre o homem e a natureza; um processo em que o homem, ao atuar sobre a natureza e modificá-la, muda sua própria natureza. 
Mészaros (2006) também segue esta lógica ao afirmar que o modo de existência humano é inconcebível sem as transformações da natureza realizadas pela atividade produtiva. Segundo este autor, os animais também trabalham e produzem, porém somente para atender às exigências práticas imediatas; a atividade dos mesmos é determinada unicamente pelo instinto ou pela experiência limitada que podem ter. O que ocorre com o homem é diferente. Anterior à realização de seu trabalho, o homem é capaz de projetá-lo, ou seja, definir em pensamento diversos meios que possibilitem o alcance de seus objetivos. Como o trabalho e a existência humana são indissociáveis, a função do pensamento é clarificar essa relação para que o homem possa reconhecer que é o seu trabalho que lhe proporciona não somente os meios de satisfazer as necessidades básicas de sobrevivência, mas também a estruturação psíquica, a transformação do ambiente em que vive e a realização pessoal.

O trabalho deve criar identidade social e transcender à necessidade de sobrevivência, ir além do conceito de emprego, fazer o homem ver-se como agente transformador do ambiente em que vive, sentir-se valorizado e reconhecido e compreender-se como artífice de seu próprio destino; por isso, conforme ressalta Moretti (2012), é tão importante que deixamos de lado a ideia de que o homem trabalha tão somente para a obtenção do salário, que nega seus sentimentos, que não se frustra com a falta de crescimento, que não se aborrece com o total descaso de gestores que apenas lhe cobram a tarefa, que lhe negam o acesso às informações, que o tratam como uma peça no processo de produção (MORETTI, 2012). O ser humano trabalhador não pode ser engolido pelas exigências do processo de consumo/produção, pois, nesta concepção, o trabalho vai sendo concebido como obrigatório, como sinônimo de sofrimento, perdendo seu sentido e características essenciais (CAMARGO; PATRÍCIO apud PATRÍCIO; CASAGRANDE; ARAÚJO, 1999). Como resultado desta situação, aumentam os índices de profissionais exauridos pelo excesso de burocracia e atividades, reforçando a falta de humanização no desenfreado processo do "progresso" civilizatório. No caso dos professores - formadores de formadores - reclamam viver em um contexto que parece próximo das relações de automação e serviços em série e, portanto, não receptivo para uma discussão eminentemente sobre a produção humana e as suas repercussões sociais. Segundo Thiele e Ahlert (2007), 
isso acontece, sobretudo, porque o trabalho em educação tem sido tratado apenas como uma atividade técnica, estruturada com conhecimentos estanques, sem prática de relações; como se não fosse construído num processo dinâmico, de interação entre pessoas e as condições do meio em que se insere, o que reforça o aspecto sobre o qual chamamos atenção neste artigo: a falta de humanização no desenfreado processo do "progresso" civilizatório.

Condições de trabalho devem significar segurança, oportunidade de crescimento profissional, descanso, salário justo, saúde, mas também desenvolvimento da capacidade criativa e reflexiva, sem comprometer, acima de tudo, a liberdade. Para isso, a esfera educacional, sobretudo a relacionada à formação de docentes (formadores de trabalhadores), precisa estar fortalecida, humanizada, organizada e consciente dos temas contemporâneos, das implicações sociais da ciência e tecnologia, dos desdobramentos que a alienação pode gerar na vida em sociedade e, consequentemente, nos ambientes de trabalho; posicionamento que se estrutura nos desígnios perseguidos pelo enfoque Ciência, Tecnologia e Sociedade (CTS), que, dentre outros, busca favorecer o desenvolvimento e a consolidação de atitudes e práticas democráticas nas questões de importância social, assim como contribuir para a eliminação do crescente abismo que vem se consolidando entre a cultura humanista e a cultura científico-tecnológica ou exclusivamente econômica (BAZZO; PEREIRA; VON LINSINGEN, 2008).

Estas rápidas considerações iniciais reforçam a intenção deste artigo: refletir sobre alguns aspectos que evidenciam que a abordagem Ciência, Tecnologia e Sociedade (CTS) nos cursos de formação de professores, pode constituir-se em importante contribuição para a promoção de ambientes de trabalho que motivem a cooperação, a humanização, a reflexão e o posicionamento crítico em substituição à competição e à sujeição.

Ressaltamos que o tema aqui em discussão se aplica a múltiplos espaços educacionais, mas, pela extensão e complexidade da questão, vamos nos concentrar prioritariamente no espaço da universidade.

Posto isso, para melhor explorar esse enfoque, utilizaremos, neste artigo, os recursos da pesquisa bibliográfica, valendo-nos de diversos autores que abordam o assunto e ressaltando a importância do enfoque CTS na formação 
de professores para impulsionar questionamentos críticos e reflexivos acerca do contexto científico-tecnológico e social e, em especial, para a promoção de ambientes de trabalho favoráveis às relações humanas.

É sobre esse e outros pontos de reflexão que trataremos na sequência.

\section{Procedimentos Metodológicos}

$\mathrm{Na}$ realização de uma pesquisa bibliográfica é imprescindível seguir caminhos e procedimentos não aleatórios, uma vez que esse tipo de pesquisa requer alto grau de vigilância epistemológica, de observação e de cuidado na escolha e no encaminhamento dos procedimentos metodológicos (SASSO DE LIMA; MIOTO, 2007). Por se pautar neste tipo de pesquisa, o presente artigo foi norteado por um esquema que é denominado por Mercado-Martínez (2004) como circular ou de aproximações sucessivas e que conta com a flexibilidade na utilização dos procedimentos a serem adotados. De acordo com esse esquema, a coleta de dados contribui tanto para a melhor definição do objeto de estudo - uma vez que as informações são obtidas provisoriamente, permitindo voltar ao material para se obter informações adicionais - quanto para aprofundar, no decorrer da análise, os aspectos que ainda se demonstram confusos ou contraditórios. Assim, alguns procedimentos foram incorporados “inicialmente", quando da formulação do projeto, de acordo com os objetivos e as propostas teóricas do estudo, mas novos procedimentos também foram incorporados "durante" o percurso de pesquisa para retificar o caminho ou as estratégias inicialmente propostas (MERCADO-MARTÍNEZ, 2004).

A leitura apresentou-se como a principal técnica, pois foi por meio dela que se pode identificar as informações e os dados contidos no material selecionado, sendo realizadas: a) leitura de reconhecimento do material bibliográfico: leitura rápida que objetivou localizar e selecionar materiais que pudessem apresentar informações e/ou dados referentes ao tema; b) leitura exploratória: também se constituiu em uma leitura rápida, exigindo, porém, conhecimento sobre o tema, domínio da terminologia e habilidade no manuseio das publicações científicas com o objetivo de verificar se as informações e/ou dados selecionados 
interessavam de fato para o estudo; c) leitura seletiva: que determinou o material que, de fato, interessava ao estudo, relacionando-o diretamente aos objetivos da pesquisa; d) leitura reflexiva ou crítica: quando foi realizado o estudo crítico do material, tendo como finalidade ordenar e sumarizar as informações ali contidas; momento de compreensão das afirmações do autor e do porquê dessas afirmações; e) leitura interpretativa: que teve por objetivo relacionar as ideias expressas na obra com o problema para o qual se buscava resposta. Implicou interpretação das ideias do autor, acompanhada de uma inter-relação destas com o propósito do pesquisador (SASSO DE LIMA; MIOTO, 2007).

Por fim, a análise e interpretação dos dados consistiu numa síntese integradora, cujo conteúdo está diluído ao longo deste artigo.

\section{Trabalho Docente: situação e desafios}

A atividade docente, assim como as demais atividades laborais, tem sido marcada por desafios significativos, reflexos das constantes transformações relacionadas ao mundo do trabalho.

As condições decorrentes deste cenário, associadas às múltiplas exigências ao papel do professor, foram ainda influenciadas por reformas educacionais e modelos pedagógicos estimulados por políticas estatais. Até a década de 60, a maior parte dos trabalhadores docentes usufruía de uma relativa segurança material, com emprego estável, bem como relativo prestígio social (JARDIM; BARRETO; ASSUNÇÃO, 2007). A partir de 1970, porém, a educação, assim como outros serviços essenciais à sociedade, participou de uma intensa expansão: do funcionalismo, dos serviços públicos gratuitos e, infelizmente, da precarização. Os reflexos desse processo foram e ainda são presenciados em vários segmentos, entre os quais o ambiente acadêmico.

Como consequência, há uma crescente depreciação da atividade docente, que é intensificada pelos baixos investimentos nas ações de melhoria da educação superior, seja do ponto de vista dos ambientes de trabalho, da remuneração ou, ainda, do reconhecimento social desse trabalho (CRUZ et al., 2010). 
Outro fator que tem exercido grande interferência na prática docente é o advento da mobilidade tecnológica, uma vez que, cada vez mais, o trabalho acompanha o professor onde ele estiver, e invade seus espaços de pessoalidade e intimidade, roubando-lhe elementos fundamentais para o pleno desenvolvimento docente: o ócio, o espaço da criatividade, da observação, da reflexão, do gestar projetos (SOUZA, 2009).

Na concepção de Enguita (1991), todo esse processo progressivamente vai tirando do professor a capacidade de decidir o exercício do seu trabalho, pois esse passa a ser preestabelecido por disciplinas, horários, programas, livros didáticos, tablets, e até mesmo pela economia e pelo mercado; isto sem falar nos conteúdos dos currículos, que, organizados e determinados por um sistema burocrático, hierarquizado e manipulador, têm como função primordial a reprodução e controle de relações econômicas e políticas ligadas a relações de poder na sociedade (CIVIERO et al., 2012).

Somado a isso, os docentes das universidades enfrentam sobrecarga de trabalho por causa das exigências das entidades de fomento à pesquisa que demandam cada vez mais a qualificação, a produção de artigos, a realização de pesquisas, a orientação de trabalhos de conclusão de curso na Graduação, de dissertações no Mestrado e de teses no Doutorado, além da realização de trabalhos de extensão e de magistério como exigências para a ascensão na carreira (OLIVEIRA, 2013). Ou, como afirma Fonseca (apud CANÔAS, 2005, p. 84), "o trabalho intelectual nas universidades, nos institutos de pesquisa (privados e públicos) vem sendo crescentemente subordinado e "taylorizado" por burocracias científicas que jogam os trabalhadores em equipes hierarquizadas de produção". Esta mentalidade da pesquisa e das publicações, como únicas variáveis para galgar postos na carreira universitária, tornou-se hegemônica ao ponto de inibir a discussão do ensino-aprendizagem (BAZZO, 2011) e promover ambientes de hostilidade e competitividade totalmente incoerentes com a proposta educacional. 
A tecnologia torna-se fim de si mesma. A sociedade afunda-se na compulsão do trabalho, da produtividade, do consumo, imprimindo sobre as pessoas pressões de eficiência que robotizam todos os cantos da vida. Inovar e produzir passa a definir a qualidade de vida (DEMO, 2001).

No âmbito da educação e, especialmente, na categoria professor-trabalhador, o status ocupacional deste profissional categoriza-o como um trabalhador alienado, dada a pauperização material, espiritual e intelectual a que vem sendo submetido (SOUZA, 2009).

Neste cenário, a certeza da incerteza ou a ambivalência do conhecimento e da vida (DEMO, 2000), talvez marca característica da sociedade atual, insere-nos num clima generalizado de crise. Refletir sobre os humanos, seus artefatos tecnológicos e suas maquinações, torna-se, então, um imperativo que impulsionará uma visão de mundo e exigirá um posicionamento ético ante as contradições e as desigualdades exacerbadas e o reconhecimento da importância dos recursos intangíveis, assim como refletir sobre a tal "educação libertadora" tão apregoada nos discursos da academia, cada vez mais prisioneira dos métodos quantitativos moldados pelo sistema vigente para medir eficiência/eficácia. Nessa perspectiva, Tragtenberg (2004) esclarece:

(...) os meios (técnicas) se tornam fins, os fins formativos são esquecidos; a criação do conhecimento e sua reprodução cedem lugar ao "controle" burocrático de sua produção como suprema virtude, em que "administrar" aparece como sinônimo de vigiar e punir - o professor é controlado mediante os critérios visíveis e invisíveis de nomeação; o aluno, mediante os critérios visíveis e invisíveis de exame. Isso resulta em escolas que se constituem em depósitos de alunos, como diria Lima Barreto em "Cemitério de vivos" (p. 18).

Quem deveria medir a eficiência na questão educacional é o livre-pensar. Essa concepção, no entanto, está muito distante dos herméticos grupos de $e x$ perts que pesquisam o que interessa para manter o sistema ineficiente do educar social. Ao contrário do que muitos apregoam, o desenvolvimento não está atrelado apenas ao aspecto tecnológico, que é instrumental, mas à capacidade de pensar, organizar e comandar a mudança, para participarmos dela como sujeitos históricos (DEMO, 2001). 
Embora se pense exaustivamente, na atualidade, em qualidade de educação, tacitamente é inegável o descompasso entre o que se pensa e o que se efetiva concretamente no cenário escolar. Recorrentemente, os que encontramos no campo educacional brasileiro são trabalhadores compelidos a intensificar individualmente suas forças intelectuais e físicas para abastecer um sistema que oprime, o que torna a força do trabalho individual enfraquecida e desarticulada diante das forças sociais. O professorado encontra-se anestesiado diante das demandas políticas, que decidem, por meio de leis, decretos e normativas, as condições de trabalho de cada sujeito operante no sistema educacional (SOUZA, 2009).

Neste sentido, Bazzo, Pereira e Linsingen (2008, p. 71) afirmam que é importante “(...) nos enxergarmos como educadores, e não apenas como funcionários do ensino. É cumprir programas e ir mais além: manter com alunos relações que visem ao crescimento intelectual de ambos para uma efetiva participação na civilização".

É urgente, portanto, a necessidade de preparar uma força de trabalho equipada com talentos que incorporem ao seu modelo mental e as suas atividades uma postura mais proativa, crítica e reflexiva; profissionais que, tendo em vista a complexidade do mundo em que vivem, saibam que ninguém mais detém sozinho o conhecimento necessário para que as coisas aconteçam, cuja autoimagem não seja a de "mais uma peça na engrenagem", um "recurso humano", como acontecia na era industrial, mas sim a de alguém que pensa e participa do mundo a sua volta.

\section{Educação no Trabalho e para o Trabalho na Era do Capital}

Quando se fala de trabalho docente não se pode ignorar que a educação não pertence a um microcontexto, onde alunos, professores e conhecimento circulam sem interferências externas. Existem vários outros fatores que intervém nesta relação e, entre eles, o mercado, a economia e a força motriz de seu desenvolvimento: o trabalhador. 
Não é à toa que os postulados do MEC estão relacionados, normalmente, a interesses de cunho econômico e político, como redução de custos e elevação dos índices de sujeitos escolarizados nos Estados federativos (SILVA, 2012). Esta é, na prática, a razão pela qual a economia competitiva globalizada vem, em alguns países ainda em passos lentos, apostando na educação básica de qualidade. Seu intento não é a cidadania, mas a competividade com base no manejo do conhecimento (LINSINGEN et al., 1999).

Muitos países avançados descobriram que tinham em sua força de trabalho uma proporção grande de pessoas insuficientemente educadas. Muito mais do que uma deterioração dos seus sistemas educativos, esta descoberta simplesmente revelou que essa orla menos educada da população, que sempre existiu, agora passa a atrapalhar o funcionamento da economia (CASTRO; OLIVEIRA, 1995).

Vemos todos os dias o discurso capitalista insistindo em sobrepor o mercado às pessoas, isto é, sobrepor o consumo aos laços sociais e isto traz consequências dramáticas à sociedade. Ser feliz deixa de ser uma aspiração para ser uma obrigação do homem pós-moderno; obrigação que se constitui em um projeto individual e privatizado. Para realizá-lo, é preciso ser melhor a cada dia; investir, buscar o topo do pódio, estar preparado para competir. Como a cobrança é intensa e o mercado sagaz, a obsessão pela eficiência aumenta e a pressa em conseguir sucesso material impede o tempo de elaboração do ser sujeito, induzindo-o a uma superficialidade atemorizante (DAMASCENO, 2011). A produção do saber transforma-se em uma maneira de capacitar um grande número de indivíduos para atuar no setor produtivo, com o objetivo de servir de mão de obra ao mercado de trabalho por meio de uma concepção que esteja de acordo com os interesses da classe dominante, perdendo-se de vista a formação de um ser humano crítico e criativo (FERRAZ; MARTONI; CHAMBERLAI, 2012).

O advento das novas tecnologias de produção é outro fator que tem ocasionado um aumento notável nos investimentos das empresas de alta tecnologia na formação de recursos humanos. A razão mais forte para esses altos investimentos tem a ver com a questão da estratégia de crescimento. Essas 
empresas - e as instituições de ensino também - sabem que ou continuam a desenvolver seu pessoal, ou ficam de fora da competição. Em muitos casos, são empresas intensivas em capital, quando a proporção de recursos gastos com formação, por maior que seja, tende a ser desprezível no seu faturamento global. Outras razões circunstanciais, como a preocupação com segurança ou a inevitável obsolescência das tecnologias nestes setores, levam essas empresas a investir constantemente na busca de conhecimentos. Adicionado à educação formal, os americanos, por exemplo, têm recebido de seus empregadores cada vez mais treinamento no trabalho. "As empresas têm um papel fundamental no investimento em capital humano: estão anualmente despendendo com treinamento de trabalhadores quase o mesmo valor das despesas anuais dos EUA com educação" (CRAWFORD, 1994, p. 39). Neste modelo, é essencialmente o trabalho que dita as necessidades de aprendizagem e treinamento (CASTRO; OLIVEIRA, 1995), não o sujeito ou a sociedade.

Destarte, como afirma Lara (2005 apud CANÔAS, 2005), atualmente

todas as formas criativas do trabalho são submetidas à valorização emburrecedora. Se objetivarmos criar algo, a futura criação, necessariamente, antes de existir, é analisada e se pergunta: Quanto posso ganhar com tal criação? Não se cria pela arte, pela necessidade humana de exteriorizar a capacidade criativa, cria-se, apenas, para valorização do objeto, esquecendo-se da valorização do homem (p. 130).

Assim, tudo o que pode ser aprendido no processo do trabalho diretamente, sob supervisão ou em grupos de trabalho, terá preferência sobre cursos formais. É o próprio trabalho que vai se tornando a fonte de aprendizagem (CASTRO; OLIVEIRA, 1995) e, sob nossa ótica, de alienação. Mais e mais o mercado se converte em escola, trabalhar torna-se sinônimo de aprender, aprender tornar-se requisito para fazer (CASTRO; OLIVEIRA, 1995) e fazer torna-se algo distante de refletir e de pensar.

A capacidade intelectual se torna o principal insumo e o principal produto da nova economia baseada no conhecimento. Quem sabe mais aprende mais e aprende mais depressa, e, com isso, tem mais chance de ganhar a "competição" (CASTRO; OLIVEIRA, 1995). Essa é a ideologia disseminada. O objeto de 
consumo é sempre posto em primeiro plano em detrimento do sujeito (DAMASCENO, 2011). É recorrente, ainda, a ideia de que todos os indivíduos precisam estar equipados com capacidades básicas, não pela dignidade ou criticidade que essas habilidades imprimam ao ser humano ou à sociedade, mas porque a velocidade da aprendizagem afeta a competitividade. Quem aprende mais devagar pode "perder a corrida" e ficar fora do mercado (CASTRO; OLIVEIRA, 1995).

\section{Humanização do Trabalho Docente: enfoque CTS na formação de professores}

Diante do cenário exposto, podemos verificar que, nas universidades, apesar dos esforços de alguns docentes, visualiza-se um estado crônico de dificuldades, seja por intensificação da precarização das condições de trabalho, seja pela incapacidade de contestar e promover ambientes de trabalho favoráveis ao desenvolvimento humano (CRUZ et al., 2010).

Os problemas se multiplicam em termos de processo civilizatório e muitos professores seguem embalados como se o problema fosse dos outros, como se a universidade não tivesse nada a ver com as questões sociais, eminentemente humanas. Estão vivendo como se adormecidos estivéssemos pelo "canto da sereia”. Um canto que faz insistir na produção de teorias descoladas da vida e das pessoas. É a opção por um comportamento muito defasado.

Sob esta lógica, o enfoque CTS constitui-se em uma opção teórica promissora a ser abordada nos cursos de formação de professores, visando a promoção de ambientes de trabalho que motivem a cooperação, a reflexão e o posicionamento crítico em relação ao processo civilizatório. Esse movimento tem se manifestado desde 1970, tendo sido base para construir currículos em vários países, em especial os de ciências, dando prioridade a uma alfabetização em ciência e tecnologia interligada ao contexto social. Seu caráter interdisciplinar visa a ressaltar a importância social da ciência e da tecnologia, de forma a enfatizar a necessidade de avaliações críticas e análises reflexivas sobre a relação científico-tecnológica e a sociedade (PINHEIRO; SILVEIRA; BAZZO, 2007). 
Os estudos CTSs colaboram também para a ampliação da percepção da sociedade - ou, ao menos em um primeiro momento -, dos estudantes dessa temática, sobre os condicionantes e implicações da pesquisa e do desenvolvimento científico e tecnológico. Para além de um melhor entendimento dessas relações, tais estudos dão embasamento a um posicionamento crítico e mais amplamente informado, uma base imprescindível para a construção de práticas de participação pública mais qualificada em questões relacionadas à ciência, tecnologia e inovação (CT\&I). Nesta perspectiva, é potencialmente utilizado para promover um olhar mais crítico ou mesmo uma ampliação do olhar, em relação ao mundo em que vivemos, de modo a superar a visão bastante comum em relação à neutralidade e ao determinismo da ciência e da tecnologia, visão essa que ainda é cotidianamente reproduzida no ensino e na mídia (FUCK; KÖRBES; INVERNIZZI, 2011).

A abordagem CTS pode ainda contribuir para desvelar as contradições da realidade, buscando compreendê-las de modo a propiciar a sua superação, sempre tendo em mira a qualidade de vida de todos os seres que habitam o planeta, pois a tríade CTS - Ciência-Tecnologia-Sociedade - é mais complexa que uma simples série sucessiva, e exige uma análise de suas relações recíprocas com mais rigor do que requereria a ingênua aplicação da clássica relação linear entre elas (BAZZO; BAZZO, 2011).

As discussões sobre a disciplina CTS não podem, entretanto, ser restritas aos cursos mais diretamente relacionados às questões de ciência e tecnologia, como os de ciências naturais e engenharias, devendo também ser contempladas em cursos de ciências humanas, sociais e jurídicas, entre outros, dada a centralidade das mudanças científicas e tecnológicas em nosso dia a dia e as implicações que essas mudanças têm nos âmbitos que são objeto de estudo dessas áreas (FUCK; KÖRBES; INVERNIZZI, 2011). Defendemos, sobretudo, sua centralidade nos cursos de formação de professores, uma vez que entendemos a educação como responsável pela manutenção e perpetuação de culturas, valores éticos e morais de um determinado grupo humano - circunscrito pelo tempo/ 
espaço, pelas interconexões e situações histórico-sociais -, assim como pela promoção de mudanças que se façam necessárias ao progresso da qualidade de vida dos humanos e dos seres em geral (BAZZO; BAZZO, 2011).

Por isso, não resta dúvida que o campo CTS precisa ser discutido, trabalhado, instituído, de modo a possibilitar aos estudantes (futuros profissionais), notadamente os de Ensino Superior, um entendimento introdutório sobre quais são os principais fundamentos que compõem esse conjunto bastante amplo de possibilidades de estudos e reflexões intelectuais (FUCK; KÖRBES; INVERNIZZI, 2011), entre os quais a formação de ambientes de trabalho favoráveis à reflexão, à crítica, à produção do conhecimento socialmente comprometido e à qualidade das relações.

A educação, na perspectiva CTS, vai muito além das questões relativas à incorporação dos estudantes no mercado de trabalho. Ele diz respeito à ampliação das condições para uma análise que reconheça o aspecto humano, econômico e social da C\&T e, em consequência, valorize uma ação participativa e mediadora dentro dos limites históricos, na definição das possíveis políticas a serem priorizadas.

Na concepção de Roberts (1991 apud SANTOS; MORTIMER, 2002), o enfoque CTS refere-se às inter-relações entre a explicação científica, o planejamento tecnológico, a solução de problemas e as tomadas de decisão sobre temas práticos de importância social.

Santos e Mortimer ainda sustentam que os currículos baseados no enfoque CTS

apresentam uma concepção de: (i) ciência como atividade humana que tenta controlar o ambiente e a nós mesmos, e que é intimamente relacionada à tecnologia e às questões sociais; (ii) sociedade que busca desenvolver, no público em geral e também nos cientistas, uma visão operacional sofisticada de como são tomadas decisões sobre problemas sociais relacionados à ciência e tecnologia; (iii) aluno como alguém que seja preparado para tomar decisões inteligentes e que compreenda a base científica da tecnologia e a base prática 
das decisões; e (iv) professor como aquele que desenvolve o conhecimento de e o comprometimento com as inter-relações complexas entre ciência, tecnologia e decisões (2002).

Para Santos e Schnetzler (2000), enquanto o ensino clássico se caracteriza pela organização curricular centrada no conteúdo específico das Ciências, o ensino CTS se apresenta como uma organização conceitual centrada em temas sociais. Neste ínterim, Linsingen (2007) afirma que os currículos escolares, ao serem organizados sob a forma de temas sociais, devem conter estratégias de ensino centradas na participação efetiva dos sujeitos, quando os temas são explorados com caráter multidisciplinar e os conceitos são abordados em uma perspectiva relacional, evidenciando as diferentes dimensões do conhecimento estudado.

Nesta perspectiva, Snow (1995) assevera que somente teremos um processo harmônico quando unirmos a área humana com a científico-tecnológica e tivermos clareza quanto à importância do ser em relação ao ter. Se isso não acontecer, não passará de devaneio qualquer tentativa de imprimir uma reflexão mais aprofundada sobre o relacionamento harmônico entre ciência/tecnologia/ sociedade, conhecido hoje como movimento "CTS" (BAZZO, 2012).

Auler (2003) complementa esta colocação afirmando que não é possível nem tampouco concebível reduzir o enfoque CTS a uma inovação didático/metodológica, uma vez que o mesmo deve estar vinculado a um profundo repensar do currículo, concebido a partir de problemas reais, contemporâneos, sendo a complexidade destes sinalizadora da necessidade de abordagens interdisciplinares.

Assim, cabe aos docentes sair da comodidade de currículos prontos e "engessados" e passar a discuti-los sob um enfoque crítico (CIVIERO et al., 2012). A participação dos professores na formulação, instituição e monitoramento das propostas educativas, além de cumprir com o imperativo jurídico, corresponde a um processo de aprendizagem e qualificação político-social dos trabalhadores-professores (SILVA, 2012). Para Pedro Demo (1991), os projetos elaborados sem a participação dos sujeitos, professores e alunos, têm como con- 
sequência a formação do "cidadão" cada vez mais dependente e discriminado, inapto à formulação e vivência de práticas alternativas e às ações que perpetuam as desigualdades e discriminações sociais.

Por isso, articulamos à discussão a compreensão de Lederman (2007 apud MIRANDA; FREITAS, 2008), que considera que, em uma sociedade científica e tecnologicamente avançada, o exercício da cidadania e da democracia somente será possível por meio da compreensão do empreendimento científico e das suas interações com a tecnologia e a sociedade. Isso possibilitará que qualquer cidadão reconheça o que está envolvido socialmente e lute com mais consciência pela promoção de ambientes de trabalho que motivem a cooperação, a humanização e o posicionamento crítico em relação ao processo civilizatório.

\section{Considerações Finais}

O desenvolvimento da ciência e da tecnologia tem acarretado diversas transformações na sociedade contemporânea, refletindo em mudanças nos níveis econômico, político, social e no universo do trabalho. Infelizmente grande parte dos trabalhadores, entre os quais se incluem os professores, vem assumindo um comportamento passivo e, muitas vezes, até conformado diante de questões e problemas sociais relevantes.

Como as mudanças são gradativas, percebemos que essa parcela da sociedade, em lugar da crítica e da reflexão, se acostuma e se ajusta às situações, mostrando pouca ou nenhuma reação, e, na prática, aceitando e, por vezes, intensificando problemas que limitam a qualidade da vida humana (VILCHES et al., 2008).

Na concepção de Conrado e El-Hani (2010), isto acontece porque as habilidades relacionadas ao senso crítico e a capacidade de discutir e pesquisar sobre informações relevantes para a resolução de problemas, que deveriam ser trabalhadas no Ensino Fundamental e Médio, muitas vezes não são desenvolvidas nem mesmo no Ensino Superior, criando lacunas entre a técnica e o desenvolvimento humano dos sujeitos. 
Os meios de comunicação e o sistema socioeconômico vigente, por sua vez, contribuem para a manutenção da situação. Atividades políticas pouco transparentes, políticas empresarial e industrial que desrespeitam e desvalorizam o trabalho humano, alienação social quanto às reais necessidades humanas, falta de igualdade e justiça social, avaliações e classificações profissionais arbitrárias e excludentes entre outros, são fatores que contribuem para a manutenção do status quo (PINHEIRO; SILVEIRA e BAZZO, 2007). Uma realidade recheada de critérios estabelecidos por pessoas que, ao invés de estar produzindo conhecimento, escrevendo livros, orientando alunos, ministrando aulas e pesquisando (diga-se sem financiamentos específicos), reproduz a lógica da interdição, matutando tabelas e mecanismos de controle policialescos para serem utilizados pelas burocracias, que ainda acreditam que esta forma competitiva de números seja o caminho da efetiva educação.

Felizmente, entre aqueles que não se conformam com essa realidade, há alguns educadores e pesquisadores que têm se mobilizado para uma transformação social; que necessitam de uma formação efetiva de cidadãos críticos, ativos e que estejam preparados para enfrentar e melhorar os problemas atuais e futuros. Para essa cidadania, a abordagem CTS, em todos os níveis, tem uma importante contribuição a dar (NASCIMENTO; LINSINGEN, 2006). Afinal,

o diferencial definitivo não está na tecnologia, ou na estrutura, ou nos processos e nem na escala, pois todos esses podem ser comprados pela organização. A lealdade e o comprometimento das pessoas apenas são obtidos por vontade própria, por doação. Ainda que as pessoas aceitem cumprir ordens nas quais não acreditam e com as quais não aceitam se comprometer, elas sempre poderão decidir se darão ou não o que possuem de melhor. Poderão até mesmo boicotar silenciosamente as iniciativas da empresa (SILVA, 2008, p. 6).

Por isso, o ensino, em todos os níveis, deve considerar um aprendizado integrado com a realidade em que o indivíduo vive, e, a partir dessa conexão entre o conteúdo a ser aprendido e as situações cotidianas, fornecer oportunidades para o estudante interagir com o meio, utilizar seus conhecimentos e discutir formas de solucionar os problemas sociais. 
Enxergar o outro não implica de forma alguma simplesmente aceitá-lo como é; não há prática educativa coerente se não houver inconformidade, dado que a própria palavra "educação" significa conduzir para um lugar diferente daquele em que se está. A incompreensão da gênese e desdobramentos dos valores e conhecimentos daqueles com os quais convivemos, no entanto, é um obstáculo brutal para uma relação pedagógica autônoma e produtiva (CORTELLA, 2006). Por isso, é importante fornecer ao aluno condições de compreender criticamente sua posição e seu papel na sociedade, bem como as possibilidades e os limites de sua transformação, enquanto aprende a buscar, a comunicar e a trabalhar em grupo para resolver demandas socialmente situadas (ACEVEDO, 1996).

Uma educação emancipadora passa pela concepção, formação e atitude dos docentes, que têm o papel de criar espaços, por meio do diálogo, de reflexões, de questionamentos, de poder decisório sobre as ações e soluções construídas coletivamente. Reflexões sobre ações e práticas baseadas em educação, entretanto, conferem mudanças nas posturas e métodos utilizados. Estas podem versar sobre questões muito específicas e incluem reconsiderações tanto gerais quanto específicas a respeito dos conhecimentos, das ações, das práticas, mas especialmente da formação do docente (CIVIERO et al., 2012). Afinal, "nada se muda se não houver suficiente embasamento para demonstrar que tal mudança é necessária" (BAZZO, 2011, p. 12).

Como acrescenta Canôas (2005, p. 180), "devemos ser artesões ativos do conhecimento social, devemos sempre lutar, a fim de obtermos a liberdade para criarmos e sermos os criadores".

Somente tomando consciência disso e exercendo essa prática, viveremos em um mundo em que o trabalho faz sentido: um mundo de pessoas com boas relações humanas e realizações pessoais; relações coletivas e não individuais.

\section{Referências}

ACEVEDO, J. A. La tecnología en las relaciones CTS. Una aproximación al tema. Enseñanza de las Ciencias, 14 (1), p. 35-44, 1996. 
ALVES, E. F. Programas e ações em qualidade de vida no trabalho. Revista Interfacehs, v. 6, n. 1, abr. 2011. Disponível em: <http://www.revistas.sp.senac. br/index.php/ITF/article/viewFile/168/180>. Acesso em: 27 out. 2016.

ANDRIOLI, A. I. O mito da competitividade. Revista Espaço Acadêmico, ano II, n. 23, abr. 2003. Disponível em: <http://www.espacoacademico.com. br/023/23and.htm>. Acesso em: 15 set. 2016.

ANTUNES, C. Acerca da indissociabilidade entre as categorias trabalho e educação. Motrivivência, ano XXII, n. 35, p. 41-61, dez. 2010. Disponível em: $<$ https://periodicos.ufsc.br/index.php/motrivivencia/article/>. Acesso em: 11 nov. 2016.

AULER, D. Alfabetização científico-tecnológica: um novo “paradigma”? Ensaio Pesquisa em Educação em Ciências, 5 (1), 1-16, 2003. Disponível em: <http:// www.fae.ufmg.br/ensaio/v5_n1/516.pdf>. Acesso em: 20 set. 2014.

BAZZO, W. A. Ciência, tecnologia e sociedade: e o contexto da educação tecnológica. 3. ed. rev. Florianópolis: Ed. da UFSC, 2011.

Cultura científica versus humanística: A CTS é o elo? Revista Ibero-americana de Educação. Organização dos Estados Ibero-Americanos para a Educação, a Ciência e a Cultura (OEI), n. 58, jan./abr. 2012. Disponível em: $<$ http://www.rieoei.org/rie_revista.php?numero=rie58a03\&titulo=Walter\%20 Antonio\%20Bazzo>. Acesso em: 21 out. 2016.

BAZZO, W. A.; PEREIRA, L. T. V.; VON LINSINGEN, I. Educação tecnológica: enfoques para o ensino de engenharia. 2. ed. rev. e ampl. Florianópolis: Ed. da UFSC, 2008.

BAZZO, J. L. S.; BAZZO, W. A. Interseções CTS, do Direito à Engenharia: o humano como fundamento básico. CONGRESSO BRASILEIRO DE EDUCAÇÃO EM ENGENHARIA (COBENGE), 39., 2011, Blumenau. Anais.., Blumenau, Santa Catarina, out. 2011. Disponível em: <http://www.nepet.ufsc. br/Artigos/COBENGE2011>. Acesso em: 18 out. 2013.

BRANDÃO, V. et al. Brasil inovador: o desafio empreendedor: 40 histórias de sucesso de empresas que investem em inovação. Brasília: Editora Expressão, 2006.

CANÔAS, J. W. A busca da canastra do mundo do trabalho. São Paulo: Unesp, 2005.

CASTRO, C. M.; OLIVEIRA, J. B. A. Os recursos humanos para a Ciência e Tecnologia. Estudo realizado pela Escola de Administração de Empresas da Fundação Getúlio Vargas por solicitação do Ministério da Ciência e Tecnologia e 
do Banco Mundial, dentro do Programa de Apoio ao Desenvolvimento Científico e Tecnológico (PADCT II), 1995. Disponível em: <http://www.schwartzman. org.br/simon/scipol/pdf/rhumanos.pdf>. Acesso em: 22 abr. 2015.

CIVIERO, P. A. G. et al. A formação do docente como determinante na concepção de uma educação democrática para transformação social. CONGRESO INTERNACIONAL DE EDUCACIÓN SUPERIOR, 8., 2012, Habana. Anais... Habana, 2012. p. 2.702-2.710. Disponível em: <http://www.nepet.ufsc.br/artigos. php?p=0>. Acesso em: 20 out. 2016.

CONRADO, D. M.; EL-HANI, C. N. Formação de cidadãos na perspectiva CTS: reflexões para o ensino de ciências. SIMPÓSIO NACIONAL DE ENSINO DE CIÊNCIA E TECNOLOGIA, 2., 2010, Anais... out. 2010. Disponível em: <http:// www.sinect.com.br/anais2010/artigos/CTS/11.pdf>. Acesso em: 18 ago. 2016.

CORTELLA, M. S. A escola e o conhecimento: fundamentos epistemológicos e políticos. 10. ed. São Paulo: Cortez; Instituto Paulo Freire, 2006.

COUTINHO JORGE, M. A.; BASTOS, F. C. P. Trabalho e capitalismo: uma visão psicanalítica. Revista Trivium - Estudos Interdisciplinares Psicanálise e Cultura, ano 1, ed. Rio de Janeiro, 2009. Disponível em: <http://www.uva.br/ trivium/edicao1/artigos-tematicos/2-trabalho-e-capitalismo.pdf $>$. Acesso em: 12 set. 2016.

CRAWFORD, R. Na era do capital humano: o talento, a inteligência e o conhecimento como forças econômicas, seu impacto nas empresas e nas decisões de investimento. São Paulo: Ed. Atlas, 1994.

CRUZ, R. M. et al. Saúde docente, condições e carga de trabalho. Revista Electrónica de Investigación y Docencia (Reid), 4, jul. 2010. Disponível em: <http:// www.ujaen.es/revista/reid/revista/n4/REID4art8.pdf>. Acesso em: 15 ago. 2016.

DAMASCENO, B. S. A sociedade contemporânea e seus meios de competência: uma crítica ao coaching à luz da teoria psicanalítica. 2011. Dissertação (Mestrado), 2011. Disponível em: <http://www.uva.br/trivium/edicoes/edicao-i-ano-iiii/resumo-das-dissertacoes/a-sociedade-contemporanea-e-seus-meios-de-competencia-uma-critica-ao-coaching-a-luz-da-teoria-psicanalitica.pdf $>$. Acesso em: 9 set. 2016.

DE MASI, D. O futuro do trabalho: fadiga e ócio na sociedade pós-industrial. Rio de Janeiro: José Olympio; Brasília, DF: Ed. da UnB, 1999.

DEMO, P. Certeza da incerteza: ambivalências do conhecimento e da vida. Brasília: Plano, 2000.

Desafios modernos da educação. 11. ed. Petrópolis, RJ: Vozes, 2001. 
DEMO, P. Pobreza política. São Paulo: Cortez; Autores Associados, 1991.

ENGUITA, M. F. A ambiguidade da docência: entre o profissionalismo e a proletarização. Revista Teoria \& Educação, n. 4, 1991.

FERRAZ, D. L. S.; MARTONI, V. B. M.; CHAMBERLAI, D. Modelo Hélice Tríplice: um mecanismo econômico e ideológico para concretizar os interesses do capital. Cad. de Pesq. Interdisc. em Ciências Humanas, Florianópolis, v. 13, n. 103, p. 115-145, ago./dez. 2012. Disponível em: <https:// periodicos.ufsc.br/index.php/cadernosdepesquisa/article/viewFile/1984-8951.2012v13n103p115/23793 >. Acesso em: 21 set. 2016.

FUCK, M. P.; KÖRBES, C.; INVERNIZZI, N. CTS no ensino superior: oportunidades e desafios de uma área em (trans)formação. Revista Iberoamericana de Ciencia, Tecnología y Sociedad (CTS), vol. 8, n. 24, jul. 2011. Disponível em: <http://www.revistacts.net/files/CTS\%20NO\%20ENSINO\%20SUPERIOR. pdf>. Acesso em: 22 set. 2016.

JARDIM, R.; BARRETO, S. M.; ASSUNÇÃO, A. A. Condições de trabalho, qualidade de vida e disfonia entre docentes. In: Cad. Saúde Pública, Rio de Janeiro, 23(10), p. 2.439-2.461, 2007.

JESUS, T. de. O trabalho do trabalho do homem, 2003. Disponível em: <http:// www.cuidardoser.com.br>. Acesso em: 2 out. 2006.

JURBERG, M. B. Individualismo e coletivismo na psicologia social: uma questão paradigmática. Paradigmas em psicologia social: a perspectiva latino-americana. Petrópolis, RJ: Vozes, 2000. p. 118-166.

LINSINGEN, I. V. et al. Formação do engenheiro: desafios da atuação docente, tendências curriculares e questões da educação tecnológica. Florianópolis: Ed. da UFSC, 1999.

LINSINGEN, I. V. Perspectiva educacional CTS: aspectos de um campo em consolidação na América Latina. Ciência \& Ensino, 1 (número especial), 2007.

MARX, K. O capital. São Paulo: Abril Cultural, 1983. V. I, tomo 1.

MERCADO-MARTÍNEZ, F. J. O processo de análise qualitativa dos dados na investigação sobre serviços de saúde. Pesquisa qualitativa de serviços de saúde. Rio de Janeiro: Vozes, 2004. p. 137-174.

MÉSZÁROS, I. A teoria da alienação em Marx. São Paulo: Boitempo Editorial, 2006. 
MIRANDA, E. M.; FREITAS, D. A compreensão dos professores sobre as interações CTS evidenciadas pelo questionário VOSTS e entrevista. Alexandria Revista de Educação em Ciência e Tecnologia, v. 1, n. 3, p. 79-99, nov. 2008. Disponível em: <https://periodicos.ufsc.br/index.php/alexandria/article/ view/37830>. Acesso em: 11 set. 2016.

MORETTI, S. Qualidade de vida no trabalho x auto realização humana, 2012. Disponível em: <http://www.posuniasselvi.com.br/artigos/rev03-12.pdf>. Acesso em: 27 out. 2016.

NASCIMENTO, T. G.; LINSINGEN, I. V. Articulações entre o enfoque CTS e a pedagogia de Paulo Freire como base para o ensino de ciências. Convergência: Revista de Ciencias Sociales, (42), 1.405-1.435, 2006.

OLIVEIRA, F. Precarização dos cargos para sustentar expansão sem planejamento. Revista Andes Especial, abr. 2013.

PALMIERI, M. W. A.; BRANCO, A. U. Cooperação, competição e individualismo em uma perspectiva sócio-cultural construtivista. Psicol. Reflex. Crit. [on-line]. 2004, vol. 17, n. 2, p. 189-198. Disponível em: <http://www.scielo. br/scielo.php?script=sci_arttext $\&$ pid=S0102-79722004000200007>. Acesso em: 13 de nov. 2016.

PATRÍCIO, Z. M.; CASAGRANDE, J. L.; ARAÚJO, M. F. Qualidade de vida do trabalhador: uma abordagem qualitativa do ser humano através de novos paradigmas. Florianópolis: PCA (1999).

PINHEIRO, N. A. M.; SILVEIRA, R. M. C. F.; BAZZO, W. A. Ciência, Tecnologia e Sociedade: a relevância do enfoque CTS para o contexto do ensino médio. Revista Ciência \& Educação, v. 13, n. 1, p. 71-84, 2007. Disponível em: <http:// www.scielo.br/pdf/ciedu/v13n1/v13n1a05.pdf>. Acesso em: 11 nov. 2016.

RODRIGUES, M. V. C. Qualidade de vida no trabalho: evolução e análise no nível gerencial. Rio de Janeiro: Vozes, 1994.

SALDANHA, R. Para compreender o trabalhador do conhecimento, 2011. Disponível em: <http://ricardosaldanha.wordpress.com/2004/06/23/para-compreender-o-trabalhador-do-conhecimento/>. Acesso em: 9 set. 2016.

SANTOS, W. L. P.; MORTIMER, E. F. Uma análise de pressupostos teóricos da abordagem CTS (Ciência - Tecnologia - Sociedade) no contexto da educação brasileira. Ensaio Pesquisa em Educação em Ciências, vol. 2, n. 2, dez. 2002. Disponível em: <http://www.portal.fae.ufmg.br/seer/index.php/ensaio/article/ viewFile/21/52>. Acesso em: $1^{\circ}$ out. 2016. 
SANTOS, W. L. P.; SCHNETZLER, R. P. Educação em Química: compromisso com a cidadania. Ijuí: Ed. Unijuí, 2000.

SASSO DE LIMA, T. C.; MIOTO, R. C. T. Procedimentos metodológicos na construção do conhecimento científico: a pesquisa bibliográfica. Rev. Katál., Florianópolis, v. 10, n. esp., p. 37-45 2007. Disponível em: <http://www.scielo. br/pdf/rk/v10nspe/a0410spe.pdf>. Acesso em: 10 abr. 2017.

SILVA, A. G. A. Participação, trabalho docente e (re)formação humana. ENCONTRO NACIONAL DE DIDÁTICA E PRÁTICAS DE ENSINO (ENDIPE), 16., 2012, Campinas. Anais... Campinas: Unicamp, 2012.

SILVA, N. Subjetividade. Psicologia social contemporânea: Livro-texto. 3. ed. Petrópolis, RJ: Vozes, 1999. P. 168-180.

SILVA, S. T. Valorização do capital humano como fator de retenção de talentos, 2008. Disponível em: <http://www.administradores.com.br/informe-se/artigos/valorizacao-do-capital-humano-como-fator-de-retencao-de-talentos/20929/>. Acesso em: 22 set. 2016.

SNOW, C. P. As duas culturas e uma segunda leitura. São Paulo: Edusp, 1995.

SOUZA, F. L.; PEDROSA, E. M. P. O enfoque CTS e a pesquisa colaborativa na formação de professores em Ciências. Rev. Areté, Manaus, v. 4, n. 7, p. 24-33, ago./dez. 2011. Disponível em: <http://www.revistas.uea.edu.br/download/revistas/arete/vol.4/ arete_v4_n07-2011-p.24-33.pdf>. Acesso em: 15 set. 2016.

SOUZA, L. A. A. de. Trabalho docente: reflexões acerca da condição de trabalho e valorização do professor da escola pública. CONGRESSO NACIONAL DE EDUCAÇÃO (EDUCERE), 9., ENCONTRO SUL BRASILEIRO DE PSICOPEDAGOGIA, 3., out. 2009. Anais... Out. 2009. Disponível em: <http://www.pucpr.br/eventos/educere/educere2009/anais/pdf/2692_1603.pdf >. Acesso em: 9 set. 2016.

THIELE, M. E. B.; ALHLERT, A. Condições de trabalho docente: um olhar na perspectiva do acolhimento. Estado do Paraná - Programa de Desenvolvimento Educacional (PDE). Unioeste. 2007. Disponível em: <http://www.diaadiaeducacao.pr.gov.br/portals/ pde/arquivos/857-4.pdf>. Acesso em: 17 ago. 2016.

TRAGTENBERG, M. Sobre educação, política e sindicalismo. São Paulo: Ed. Unesp, 2004.

VILCHES, A. et al. Obstáculos que pueden estar impidiendo la implicación de la ciudadanía y, en particular, de los educadores, en la construcción de un futuro sostenible. Formas de superarlos. Revista CTS, 11(4), p. 139-162, 2008.

Recebido em: 13/11/2016

Aceito em: 10/7/2017 